\title{
Dexamethasone-induced hyposensitivity to rocuronium in rat diaphragm associated with muscle-fiber transformation
}

\author{
DAN CHEN, MEI-RONG YANG, LI-NA HUANG, YU-WEI QIU and SHI-TONG LI \\ Department of Anesthesiology, First People's Hospital, School of Medicine, \\ Shanghai Jiaotong University, Shanghai 200030, P.R. China
}

Received April 3, 2013; Accepted November 13, 2013

DOI: $10.3892 / \mathrm{mmr} .2013 .1819$

\begin{abstract}
The aim of the current study was to investigate the effect of chronic dexamethasone (Dex) administration on rat diaphragm function and sensitivity to rocuronium and muscle-fiber transformation. Adult male Sprague-Dawley rats were randomized to receive a daily intraperitoneal injection of Dex to evaluate whether alterations in diaphragm function and susceptibility to rocuronium would be induced. In addition, diaphragm contractile properties, histopathology and isometric twitch tensions of nerve-hemidiaphragm preparations were evaluated. Dex administration led to impaired diaphragm force generation, increased fatigue resistance and a prolonged half-relaxation time, as well as time-to-peak tension. Dex treatment led to desensitization of the rat diaphragm to rocuronium, as demonstrated by a shift of the rocuronium concentration-twitch tension curves to the right. Histochemical analysis of adenosine triphosphatase revealed that the distribution and cross-sectional area of type II fibers were decreased in rats exposed to Dex. The present study indicates that chronic Dex treatment induced alterations in muscle function and that susceptibility to rocuronium is associated with muscle fiber-type transformation, which may aid in directing future administration of muscle relaxants.
\end{abstract}

\section{Introduction}

Muscle atrophy, dysfunction and resistance to non-depolarizing neuromuscular blocking agents are commonly associated with glucocorticoid (GC) treatment. Previous studies have reported that partial recovery or termination of pancuronium-induced paralysis occurs following large doses of steroid administration (1-3). Soltész et al found a shorter duration of atracurium and rocuronium-induced neuromuscular blockage in patients

Correspondence to: Dr Shi-Tong Li, Department of Anesthesiology, First People's Hospital, School of Medicine, Shanghai Jiaotong University, 100 Haining Road, Shanghai 200080, P.R. China E-mail: zhngweilv@126.com

Key words: steroid, non-depolarizing muscle relaxant, fiber type, atrophy, diaphragm, contractile property receiving long-term prednisolone medication $(4,5)$. In addition, a retrospective clinical review showed that patients receiving long-term pretreatment with betamethasone required $75 \%$ more vecuronium (6). Preclinically, Arts et al reported that the neuromuscular blocking effect of d-tubocurarine at two doses and low-dose hemicholinium-3 may be partially or wholly antagonized by prednisolone (7). Additionally, Robinson et al and Parr et al reported betamethasone-induced resistance to atracurium and vecuronium $(8,9)$.

Findings of previous in vitro studies have indicated that GCs have presynaptic facilitatory effects on neuromuscular transmission at low concentrations (10-15). The presynaptic effects are associated with enhanced active uptake of choline into the nerve terminal, resulting in increased synthesis and the release of acetylcholine (ACh). This effect may contribute to resistance to neuromuscular blocking drugs following GC treatment (15). However, it is unclear whether these in vitro observations apply in vivo, particularly when GCs are administered chronically.

Skeletal muscle atrophy induced by GCs is characterized by a decrease in the size of fast-twitch or type II muscle fibers with little or no impact observed on slow-twitch or type I fibers. Skeletal muscle atrophy is also accompanied by a reduction in the relative contribution of type II fibers to total muscle fibers (16-21). Respiratory and peripheral muscles are affected by corticosteroid treatment and GC-induced atrophy of the diaphragm is often observed in clinical practice $(21,22)$. The diaphragm is composed of $40 \%$ type I and $60 \%$ type II fibers (23). A shift towards slow-twitch fibers induced by steroids may cause a marked impairment in diaphragm function. Notably, GC-induced changes in isotonic contractile properties due to an altered diaphragm-type composition have been demonstrated in a number of animal studies (24-27).

Mechanisms of resistance to non-depolarizing muscle relaxants (NDMRs) in GC treatment have not been investigated extensively. Aside from featuring various contractile properties, the type II fiber is more sensitive to NDMRs compared with the type I fiber. As the planar area of the motor endplate in a type II fiber is much larger compared with type I, the sarcoplasmic reticulum density is twice that of the type I fiber. Drugs enter the former junction more rapidly than the latter (28-30). The composition of muscle fiber-types establishing various sensitivities to particular muscle relaxants has been observed in a number of clinical studies (31-36). 
Donati et al examined vecuronium neuromuscular blockage of two skeletal muscles in adult females and observed that the adductor larynx, which contained mainly type II fibers, showed a faster onset of muscle relaxant compared with the adductor pollicis, which contained primarily type I fibers (36). Day et al compared the $\mathrm{ED}_{50}$ of pancuronium in two muscle types, the gastrocnemius (fast twitch) and soleus (slow twitch) and found that the gastrocnemius was more sensitive $\left(\mathrm{ED}_{50}\right.$, $105 \mu \mathrm{g} / \mathrm{kg}$ ) compared with the soleus $\left(\mathrm{ED}_{50}, 150 \mu \mathrm{g} / \mathrm{kg}\right)(37)$. Thus, GC-induced fiber-type transformation may be one of the mechanisms associated with resistance to the action of NDMRs.

Therefore, the aim of the current study was to investigate the effect of chronic administration of the popular steroid, Dex, on diaphragm function and on the potency of a common NDMR, rocuronium as well as to investigate whether any observed effects are associated with muscle-fiber transformation.

\section{Materials and methods}

Animals and muscle preparation. This study was approved by the Animal Care and Use Committee of the Shanghai Jiaotong University School of Medicine and was performed in compliance with the WHO International Guiding Principles for Animal Research. Sixty adult male Sprague-Dawley rats (180-220 g) were randomized into three groups $(n=20$ per group). The Dex group received a daily intraperitoneal injection of Dex $[600 \mu \mathrm{g} / \mathrm{kg}$ body mass; a dose that has been previously shown to cause significant loss of muscle mass $(17,38)]$ suspended in an isotonic vehicle $(0.9 \% \mathrm{NaCl})$ for 14 days. The saline group received an equivalent volume of saline $(0.9 \% \mathrm{NaCl})$ daily for 14 days. All injections were performed at approximately the same time of day in the two groups. A food-restricted group (fr) was pair-fed with the Dex group for 14 days to evaluate whether muscle dysfunction following Dex treatment was caused by anorexia typically associated with GC therapy. This was achieved by weighing the food intake of the Dex group rats daily and providing the fr group rats with an equivalent amount of food. Food and water was available ad libium to rats in the Dex and saline groups. Each experimental group contained 20 rats. The animals were included in the final data set.

Twenty-four hours following the final drug administration, the rats were anesthetized with pentobarbital $(60 \mathrm{mg} / \mathrm{kg}$ intraperitoneally). The left hemidiaphragm, with attached phrenic nerve and the right hemidiaphragm, both with the central tendon and ribcage intact, were rapidly removed from each rat to investigate rocuronium potency and diaphragm contractibility.

Strips of diaphragm (8-10 mm wide, cut parallel to the muscle fibers) with or without the phrenic nerve attached, were dissected for subsequent experiments. Strips obtained from the costal region of the diaphragm were embedded separately in plastic holders and rapidly frozen in isopentane cooled in liquid nitrogen $\left(-160^{\circ} \mathrm{C}\right)$, followed by further freezing in liquid nitrogen for ATPase staining. Each isolated strip was mounted vertically in a tissue chamber, fixed at the rib cage, inferiorly positioned and suspended at the central tendon from a force displacement transducer using a 3-0 silk suture (ALC-M System for Isolated Tissue-Organ Research;
$40 \mathrm{ml}$ in volume). The chamber was filled with Krebs solution, maintained at $37^{\circ} \mathrm{C}$ and bubbled with $95 \%$ oxygen $/ 5 \%$ $\mathrm{CO}_{2}$. The composition of the Krebs solution was as follows: $137 \mathrm{mM} \mathrm{NaCl}, 4 \mathrm{mM} \mathrm{KCl}, 2 \mathrm{mM} \mathrm{CaCl}, 1 \mathrm{mM} \mathrm{MgCl}_{2}$, $1 \mathrm{mM} \mathrm{KH}_{2} \mathrm{PO}_{3}, 12 \mathrm{mM} \mathrm{NaHCO}$ and $6.5 \mathrm{mM}$ glucose, with a $\mathrm{pH} 7.40 \pm 0.05$ during bubbling. Isometric tension was elicited by indirect (phrenic nerve) or direct (muscle) supramaximal constant-voltage stimulation at $0.1 \mathrm{~Hz}$ for 0.05 and $0.2 \mathrm{msec}$ in the cases of indirect and direct stimulation, respectively, using a stimulator and a constant-voltage unit. The twitch tension was recorded via the force transducer on a recorder (ALC-MPA 2000m, Acquisition and Analysis System for Life Science Research, Shanghai Alcott Biotech, Shanghai, China). The stimulator was activated by a personal computer. Twitch stimuli were used to determine the optimal length $\left(\mathrm{L}_{0}\right)$ at which skeletal muscle may generate the greatest force, followed by a 15 -min thermoequilibration period. A number of measurements were performed as described in subsequent sections.

\section{Diaphragm contractile properties}

General. For direct stimulation, the diaphragm was placed between two large silver electrodes and pretreated with a sufficient concentration $(12 \mu \mathrm{M})$ of d-tubocurarine to completely eliminate neuromuscular transmission.

Twitch characteristics. Five twitches were recorded at $\mathrm{L}_{0}$ to obtain maximal twitch force $\left(\mathrm{P}_{\mathrm{t}}\right)$, time-to-peak tension (TPT) and half-relaxation time (1/2RT). The average values were used for subsequent analysis.

Maximal tetanic contraction. Two maximal tetanic stimuli, with a frequency of $120 \mathrm{~Hz}$ and a train duration of $250 \mathrm{msec}$ were generated to obtain the maximal tetanic force $\left(\mathrm{P}_{0}\right)$.

Force-frequency instructions. Muscle bundles were stimulated every $2 \mathrm{~min}$ at the following frequencies: 10, 20, 40, 60, 80 and $120 \mathrm{~Hz}$ (train duration, $250 \mathrm{msec}$ ).

Fatigue properties. Bundles were fatigued by means of $330 \mathrm{msec}$ stimulations repeated at $25 \mathrm{~Hz}$ and applied every sec for $5 \mathrm{~min}$ as described by Burke et al with modifications. Fatigue index (fatigue), adapted from Burke, is expressed as the ratio of the tetanus force developed at $120 \mathrm{sec} /$ the maximal force developed by tetanus (39). Following the experiment, the muscle was weighed and the cross-sectional area (CSA) was estimated based on the formula: muscle weight $(\mathrm{g}) /\left[\mathrm{L}_{0}(\mathrm{~cm}) \times 1.056\left(\mathrm{~g} / \mathrm{cm}^{3}\right)\right]$, assuming muscle density is $1.056 \mathrm{~g} / \mathrm{cm}^{3}$ (26). Forces were normalized against the CSA of the muscle segments.

Rocuronium potency. For indirect stimulation, the phrenic nerve was positioned on wire bipolar silver electrodes. After the elicited twitch tension had been stabilized for a minimum of $15 \mathrm{~min}$, the single-twitch tension, averaged in groups of five, was determined. Rocuronium was then applied to the preparation. Drug concentrations were determined by adding freshly prepared solutions with calibrated micropipettes to modified Krebs solution $(40 \mathrm{ml})$ in the tissue chamber. Following stabilization of the drug effect for a minimum of $10 \mathrm{~min}$, single-twitch tension was again determined. Data were accepted when twitch tension returned to $95-105 \%$ of the initial value by rinsing the diaphragm preparation with 
Krebs solution in each study. Rocuronium bromide was obtained from N.V. Organon (Oss, The Netherlands) and all other drugs were purchased from Sigma-Aldrich (St. Louis, MO, USA). Indirectly elicited twitch tension in the same preparation with no neuromuscular blocker was defined as the control value.

ATPase staining. Muscle blocks were serially sliced at $5 \mu \mathrm{m}$ on a cryostat (Leica CM1850, Nussloch, Germany). The modified ATPase staining method was applied in addition to hematoxylin and eosin (H\&E) staining.

Muscle fiber types were classified as type I or II based on their staining for myofibrillar ATPase following alkaline $\mathrm{pH} 10.4$ and acid $\mathrm{pH} 4.5$ using a modification of the procedure described by Brooke et al (40) and the criteria outlined by Peter et al (41). The image analysis software Image-Pro Plus, version 5.1 (Media Cybernetics, Silver Spring, MD, USA) was used to evaluate the prepared samples. Then, 400 fibers/muscle were measured for muscle fiber-type distribution and CSA of each fiber type. The distribution of muscle fibers of a given fiber type (type I or II) was expressed as a percentage of all the fibers in the section.

Statistical analysis. Statistical analyses were performed using the SPSS/PC+ package (SPSS INC., Chicago, IL, USA). Data are expressed as mean \pm SD and were compared using one- or two-way repeated-measures ANOVA with post hoc Bonferroni testing. Otherwise repeated-measures ANOVA was used for force-frequency and the growth curve analysis. $\mathrm{P}<0.05$ was considered to indicate a statistically significant difference.

\section{Results}

Body weight. There was no difference in the initial body weight between groups $(\mathrm{P}>0.05)$. Food intake decreased markedly in all animals during the study, particularly in the initial three days following Dex treatment (data not shown). At the end of the 14-day treatment period, the body weights in the three experimental groups were significantly different from one another $(\mathrm{P}<0.01$; Table I). Repeated-measures ANOVA revealed a significant effect of treatment on body weight during the study (Fig. 1).

\section{Diaphragmatic contractile properties.}

There was no significant difference between groups with regard to diaphragm size (width and length) or in twitch tensions elicited by indirect or direct stimulation (7.8-17.4 g; $\mathrm{P}>0.05$; Fig. 2A and B).

Twitch characteristics and maximal tetanic tension. Data from the contractile properties of the diaphragm are summarized in Table II. $\mathrm{P}_{0}$ corrected by CSA $\left(\mathrm{kg} / \mathrm{cm}^{2}\right)$ decreased in the Dex group $(\mathrm{P}<0.05) . \mathrm{P}_{\mathrm{t}}$ and $\mathrm{P}_{\mathrm{t}} / \mathrm{P}_{0}$ were decreased in the Dex group, however, these differences did not reach statistical significance. TPT and 1/2RT were significantly prolonged in the Dex group compared with the other two groups $(\mathrm{P}<0.05)$.

Force-frequency curve. The response of diaphragm strips to increasing stimulus frequencies is shown in Fig. 3. A significant downward shift between 40 and $120 \mathrm{~Hz}$ was observed in the Dex group (Fig. 3).
Table I. Effect of experimental treatment on body weight.

\begin{tabular}{lcc}
\hline \multirow{2}{*}{ Group } & \multicolumn{2}{c}{ Body weight } \\
\cline { 2 - 3 } & Initial, g & Final, g \\
\hline Dex & $197.55 \pm 2.688$ & $171.10 \pm 2.812^{\mathrm{a}, \mathrm{b}}$ \\
Saline & $194.70 \pm 2.163$ & $280.95 \pm 2.423$ \\
Fr & $199.55 \pm 1.941$ & $209.70 \pm 2.43^{\mathrm{a}}$ \\
\hline
\end{tabular}

Values are expressed as mean $\pm \mathrm{SD}(\mathrm{n}=20)$. Statistical analysis was performed by one-way ANOVA with post-hoc Bonferroni testing. ${ }^{\mathrm{a}} \mathrm{P}<0.05$ vs. saline; ${ }^{\mathrm{b}} \mathrm{P}<0.05$ vs. food-restricted group. Dex, dexamethasone; Fr, food-restricted.

Fatigue properties. The fatigue index was significantly higher $(\mathrm{P}<0.05)$ in the Dex group compared with the other two groups.

Rocuronium potency. Following rinsing of the diaphragms exposed to rocuronium with Krebs solution, the indirectly elicited twitch tension returned to $95-105 \%$ of the initial value in each study, which indicated that the diaphragm remained responsive.

In all the groups, rocuronium reduced the magnitude of indirectly elicited twitch tension in a concentration-dependent manner $(\mathrm{P}<0.05$ or $\mathrm{P}<0.01$; Fig. $4 \mathrm{~A}-\mathrm{C})$. $\mathrm{IC}_{50}$ values, which quantitatively indicate the position of the dose-response curve for rocuronium, were largest in the Dex group compared with the other two groups $(\mathrm{P}<0.01$; Table III). There was no significant difference in rocuronium potency between the saline and fr groups $(\mathrm{P}>0.05)$. There was no significant difference in the slope among the three groups $(\mathrm{P}>0.05$; Table III), which indicates no evident drug interaction. Dex treatment significantly shifted the concentration-twitch tension curve to the right compared with the saline group $(\mathrm{P}<0.01)$, however, there was no Dex-dependent effect compared with the fr group $(\mathrm{P}>0.05$; Fig. 4D).

Histology and histochemistry. Histological examination of H\&E-stained slides showed a normal muscular pattern of the diaphragm in the three groups. There was no inflammatory cell infiltration or newly-generated muscle fibers observed in the Dex-treated diaphragm. Morphometric analysis of ATPase-stained slides showed a significant reduction in the percentage of type II fibers in the Dex-treated group $(\mathrm{P}<0.05$; Table III). Dex treatment resulted in a significant reduction in the CSA of type II fibers $(\mathrm{P}<0.05)$ with no change in the CSA of type I fibers $(\mathrm{P}>0.05)$. In the fr group, there was generalized atrophy of all the fiber types compared with the saline group $(\mathrm{P}<0.05$; Figs. 5 and 6; Table IV).

\section{Discussion}

Over the 14-day period, the normal increase in body weight observed in rats treated with saline was attenuated by Dex treatment. Since alterations in nutritional status alone affect the morphology and function of the rat diaphragm, interpretation of the direct effects of Dex treatment is confounded $(42,43)$. 
Table II. Diaphragmatic contractile properties.

\begin{tabular}{lllllll}
\hline Group & $\mathrm{P}_{\mathrm{t}}\left(\mathrm{kg} / \mathrm{cm}^{2}\right)$ & TPT $(\mathrm{msec})$ & $1 / 2 \mathrm{RT}(\mathrm{msec})$ & $\mathrm{P}_{0}\left(\mathrm{~kg} / \mathrm{cm}^{2}\right)$ & $\mathrm{P}_{\mathrm{t}} / \mathrm{P}_{0}$ & Fatigue $(\%)$ \\
\hline Dex & $0.17(0.05)$ & $23.3(2.26)^{\mathrm{a}, \mathrm{b}}$ & $24.3(2.12)^{\mathrm{a}, \mathrm{b}}$ & $0.63(0.12)^{\mathrm{a}, \mathrm{b}}$ & $0.27(0.04)$ & $49.6(8.72)^{\mathrm{a}, \mathrm{b}}$ \\
Saline & $0.21(0.06)$ & $19.6(1.98)$ & $20.2(2.54)$ & $0.92(0.31)$ & $0.23(0.06)$ & $34.6(9.64)$ \\
Fr & $0.21(0.05)$ & $20.9(2.34)$ & $21.4(2.95)$ & $1.00(0.37)$ & $0.21(0.05)$ & $35.8(7.93)$ \\
\hline
\end{tabular}

Data are presented as mean $\pm \mathrm{SD}$. Statistical analysis was performed by one-way ANOVA with post hoc Bonferroni testing. ${ }^{\mathrm{a}} \mathrm{P}<0.05 \mathrm{vs}$. saline; ${ }^{b} \mathrm{P}<0.05$ vs. food-restricted. $\mathrm{P}_{\mathrm{t}}$, twitch tension; TPT, time-to-peak tension; $1 / 2 \mathrm{RT}$, half-relaxation time; $\mathrm{P}_{0}$, tetanic tension; $\mathrm{P}_{\mathrm{t}} / \mathrm{P}_{0}$, twitch/tetanic ratio. Dex, dexamethasone; Fr, food-restricted.

Table III. $\mathrm{IC}_{50}$ values and slopes of the concentration-twitch tension curves of rocuronium.

\begin{tabular}{lccc}
\hline Rocuronium & \multicolumn{1}{c}{ Dex } & Food-restricted & Saline \\
\hline $\log \mathrm{IC}_{50}$ & $0.920 \pm 0.0618^{\mathrm{a}, \mathrm{b}}$ & $0.816 \pm 0.0532$ & $0.786 \pm 0.0384$ \\
Slope & $-5.57 \pm 0.569$ & $-5.57 \pm 1.64$ & $-4.88 \pm 0.698$ \\
$\mathrm{IC}_{50}$ & $8.39 \pm 1.14$ & $6.60 \pm 0.838$ & $6.14 \pm 0.604$ \\
\hline
\end{tabular}

$\operatorname{logIC} \mathrm{C}_{50}, \mathrm{IC}_{50}$ and slope at $\log \mathrm{IC}_{50}$ were determined from a four-variable logistic sigmoidal dose-response model fitted to the concentration-twitch tension curves. The twitch tension was elicited by indirect stimulation at $0.1 \mathrm{~Hz}$. Values are expressed as mean $\pm \mathrm{SD}$. Statistical significance in $\mathrm{IC}_{50}$ was calculated from $\log \mathrm{IC}_{50}$. Statistical analysis was performed by one-way ANOVA with post-hoc Bonferroni testing. ${ }^{a} \mathrm{P}<0.01 \mathrm{vs}$. saline group; ${ }^{\mathrm{b}} \mathrm{P}<0.01$ vs. food-restricted group. Dex, dexamethasone; Fr, food-restricted.

Table IV. Diaphragm fiber distribution.

\begin{tabular}{lcc}
\hline & \multicolumn{2}{c}{ Fiber-type proportions, \% total } \\
\cline { 2 - 3 } Treatment & Type I & Type II \\
\hline Dex & $45.5 \pm 2.2$ & $54.2 \pm 1.9^{* 8}$ \\
Saline & $34.2 \pm 1.4$ & $63.8 \pm 1.7$ \\
Fr & $33.8 \pm 1.6$ & $66.5 \pm 2.4$ \\
\hline
\end{tabular}

Values are presented as mean \pm SD. Statistical analysis was performed by two-way ANOVA with post hoc Bonferroni testing. " $\mathrm{P}<0.05$, vs. saline group. ${ }^{\S} \mathrm{P}<0.05$, vs. food-restricted group. Dex, dexamethasone; Fr, food-restricted.

The results of the current study demonstrate that chronic Dex administration induces a selective atrophy and a reduced distribution of type II fibers in the rat diaphragm, indicating a shift towards slow fibers. This observation is consistent with previous studies (24-26). Matched food intake (fr group) caused a general atrophy of type I and II fibers and the composition of type I and II fibers was unaltered, which is consistent with observations from previous studies $(26,44,45)$. In agreement with these morphological changes, alterations in contractile properties were observed. Prolonged TPT and 1/2RT, reduced force generation at a wide range of high stimulus frequencies and resistance to fatigue, observed in the Dex group, are all consistent with the changes of muscle morphology. No significant change of muscle function was observed in the pair-fed (fr) group.
The morphological and contractile adaptations of the diaphragm in the pair-fed group were generally dissimilar to those observed in the Dex-treated animals. These results are consistent with previous studies indicating that the effects of GC treatment on diaphragm structural and functional properties may not be attributed to a non-selective catabolic effect alone (44-46).

In addition to the changes in diaphragm function and structure, a marked decrease was observed in the potency of the neuromuscular blocking action of rocuronium. In the current study, the concentration-twitch tension curve of rocuronium shifted to the right in the Dex-treated rats but not in the pair-fed rats, indicating that weight loss was caused by GC-associated anorexia itself and cannot account for the change in rocuronium potency. Therefore, the resistance to rocuronium is more likely due to Dex-induced changes in diaphragm-fiber composition.

Mechanisms of the GC-induced improved neuromuscular transmission and hyposensitivities to the neuromuscular blocking actions have not been investigated as extensively as those of muscle contractility. A number of studies have demonstrated changes in the electrophysiological properties of GC-treated neuromuscular junctions (NMJs) (10-15). For example, Van Wilgenburg et al reported that low-dose Dex and prednisolone resulted in increased miniature endplate potential (MEPP) amplitude at rat diaphragm NMJs, whereas high doses decreased MEPP amplitude $(14,47)$. Similar results at low CS doses were also reported by Dalkara and Onur (11). In their study, Wilson et al reported that prednisolone facilitated the spontaneous release of $\mathrm{ACh}$ in the rat diaphragm, as manifested by a 2-3-fold increase in MEPP frequency (48). A reduction in MEPP amplitude was observed, indicating an additional postsynaptic effect. Leeuwin et al reported an 


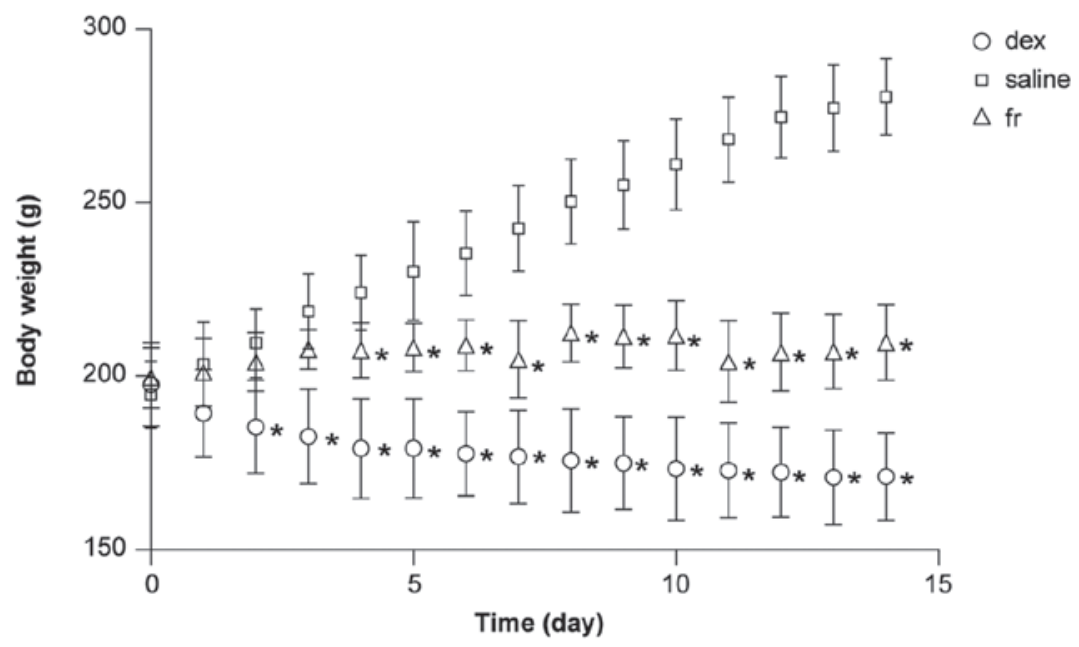

Figure 1. Body weight of the three groups during the 14-day treatment period. Values are expressed as mean \pm SD (n=20 per group). Statistical analysis was performed by two-way repeated-measures ANOVA with post-hoc Bonferroni testing ("P<0.05 vs. saline).

A

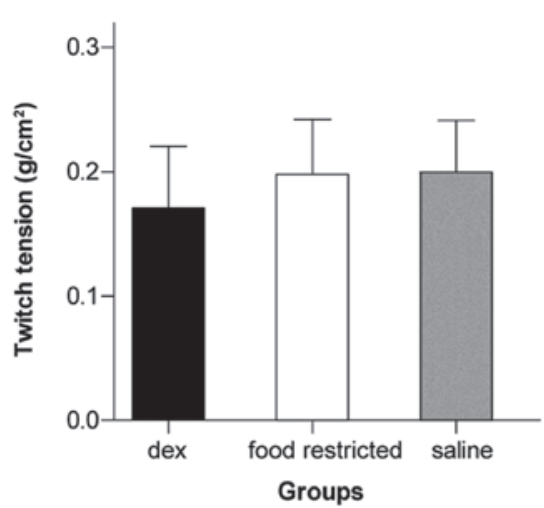

B

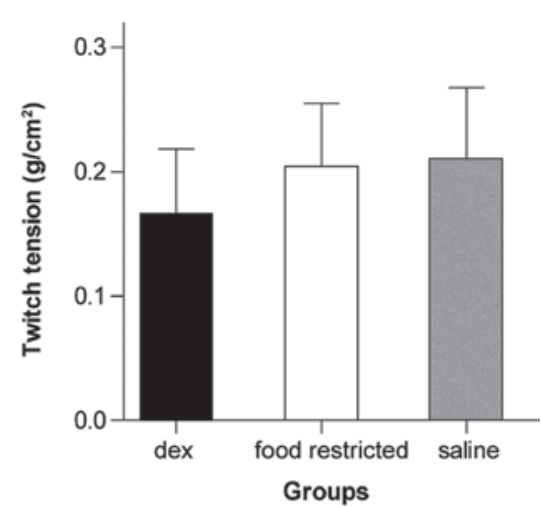

Figure 2. Single-twitch tension elicited by (A) indirect (phrenic nerve) or (B) direct (muscle) stimulation. Values are expressed as mean \pm SD ( $\mathrm{n}=20 \mathrm{per}$ group). Statistical analysis was performed by one-way ANOVA with post-hoc Bonferroni testing. Dex, dexamethasone.

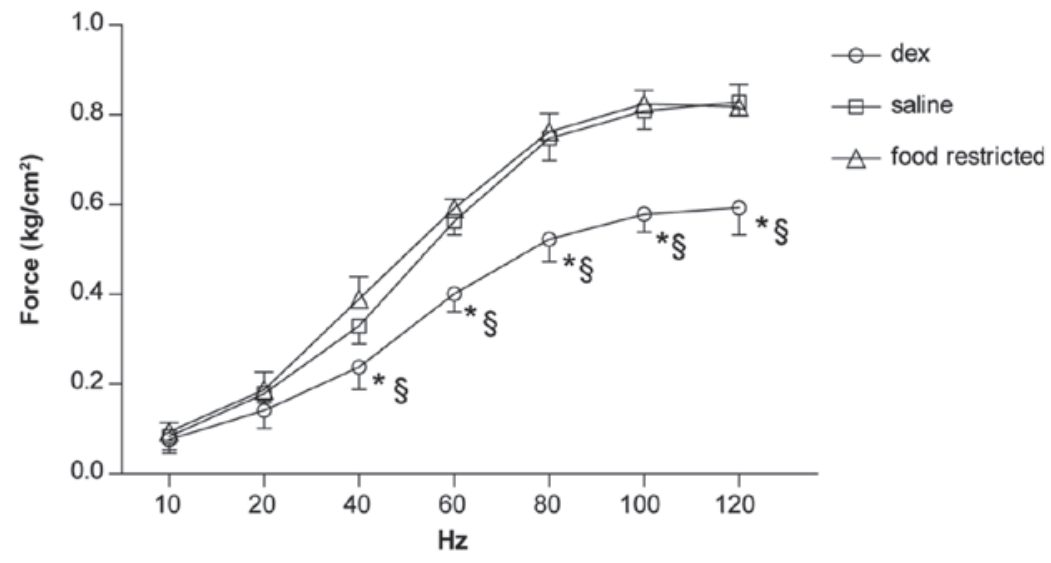

Figure 3. Force-frequency curves of diaphragm bundles. Values are presented as mean \pm SD. Statistical analysis was performed by two-way repeated-measures ANOVA with post-hoc Bonferroni testing ( $\mathrm{P}<0.05$ vs. saline; ${ }^{\circledR} \mathrm{P}<0.05$ vs. food-restricted group).

increase in synaptic vesicle size that is indicative of an increase in quantal size for neuromuscular transmission (12).

If GC treatment leads to an increase in the quantal release of ACh at the NMJ, it may be hypothesized that such an effect may improve neuromuscular transmission. However, with repetitive stimulation, an increase in the quantal release of $\mathrm{ACh}$ may lead to a rapid depletion of transmitter stores and neuromuscular transmission failure. Greater resistance to fatigue was revaled in the present study and a number of previous studies $(24,26,28)$. Furthermore, the majority of experiments 
A

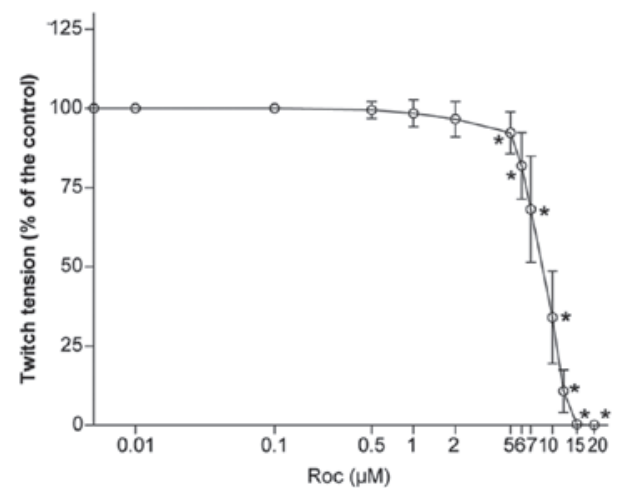

C

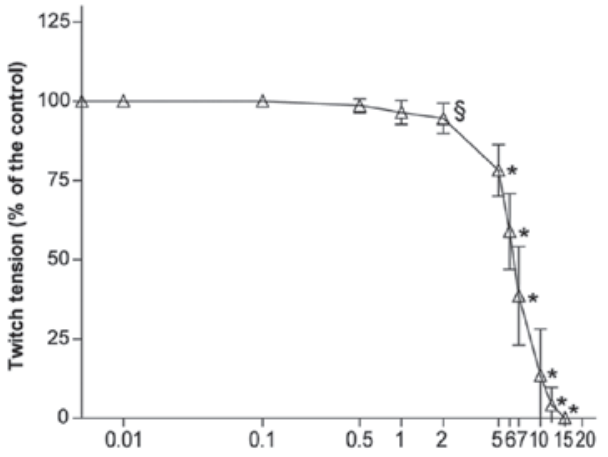

B

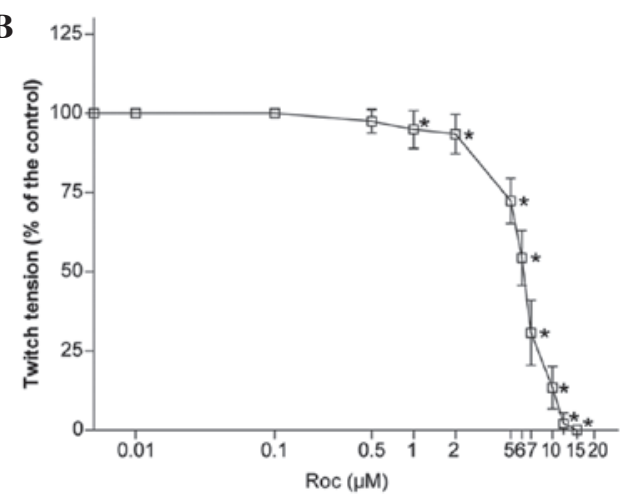

D

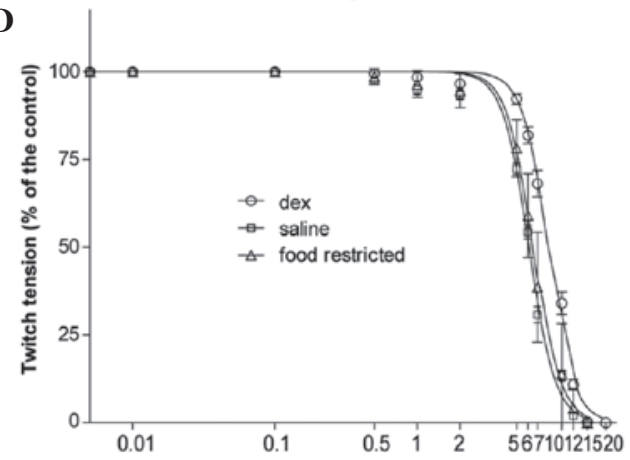

Figure 4. Concentration-twitch tension curves for rocuronium in (A) Dex, (B) saline and (C) food-restricted groups ( ${ }^{*} \mathrm{P}<0.01$ and ${ }^{\S} \mathrm{P}<0.05$, vs. control.). (D) Smooth curves derived from non-linear regression of the concentration-twitch data in three experimental groups. Values are presented as mean $\pm \mathrm{SD}(\mathrm{n}=20$ in each curve). Statistical analysis was performed by two-way repeated-measures ANOVA with post-hoc Bonferroni testing. (D) The curve was significantly shifted rightward in the Dex group compared with the saline group $(\mathrm{P}<0.01)$, while no significant difference was observed between the food-restricted and saline groups $(\mathrm{P}>0.05)$. Roc, rocuronium; Dex, dexamethasone.

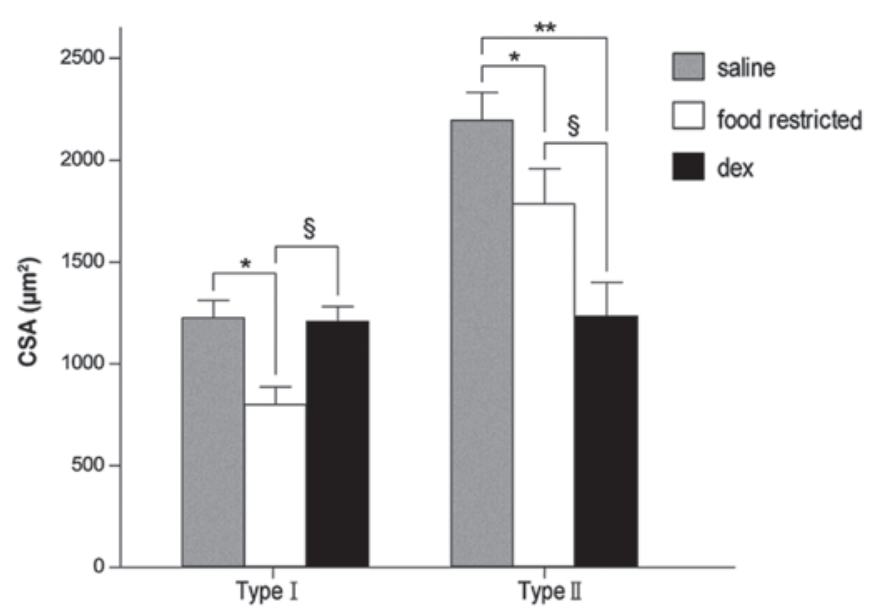

Figure 5. Fiber diameters in the three groups. Values are presented as mean \pm SD. Statistical analysis was performed by two-way ANOVA with post-hoc Bonferroni testing ( ${ }^{*} \mathrm{P}<0.05$ and ${ }^{* *} \mathrm{P}<0.01$ vs. saline group; ${ }^{\circledR} \mathrm{P}<0.05$ vs. food-restricted group). Dex, dexamethasone.

A

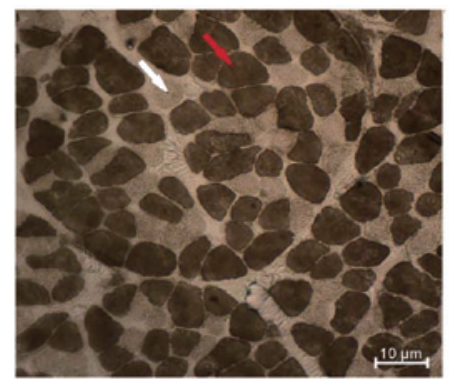

B

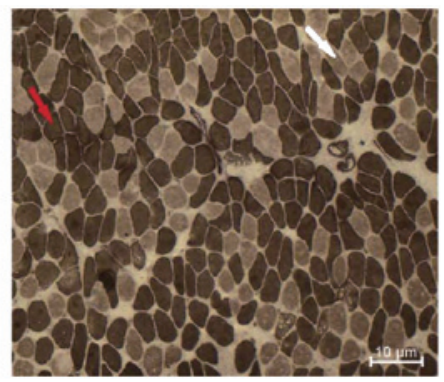

C

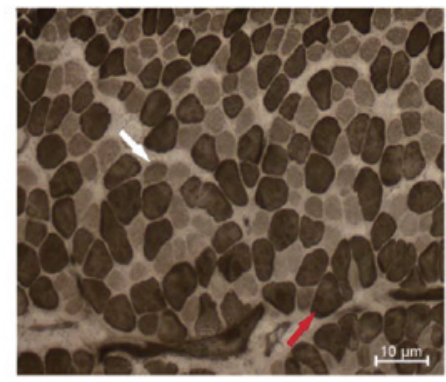

Figure 6. ATPase staining of the diaphragm at pH 10.4 in (A) saline, (B) Dex and (C) food-restricted groups. The red arrows refer to type II fibers and the white arrows refer to type I fibers (magnification, x100). 
aiming to clarify the mechanism were designed under acute conditions, whereas chronic administration of steroids is more common in clinical practice.

To the best of our knowledge, no animal studies have been performed to simultaneously examine morphological and contractile effects, as well as sensitivity to NDMRs. The present study examined the effects of Dex, a commonly used $\mathrm{GC}$, at a low dose, well within the range used clinically, on rat diaphragm structure, contractile properties and susceptibility to rocuronium. The altered diaphragm function was confirmed to be associated with fiber transformation. Furthermore, Dex-induced resistance to rocuronium is hypothesized to be associated with morphological changes.

Dex was selected as a suitable corticosteroid in the present study as it is a fluorinated drug with minimal mineralocorticoid content and marked GC activity (49). In humans, Dex is administered intravenously or intramuscularly at $6 \mathrm{mg}$ /day for thrombocytopenia (50). Prolonged Dex administration at doses of 4-16 mg daily are frequently used during intensive care unit hospitalization (51). Dex was also selected since long-term Dex administration has a marked antagonizing effect on the neuromuscular block caused by hemicholinium-3 and d-tubocurarine $(13,52-54)$. It is well-established that among various species, the male rat is similar to humans with respect to Dex metabolism (55). Intravenous low-dose Dex (0.3-0.5 mg/kg/day) was demonstrated to be efficacious during endotoxemia and pulmonary fibrosis in rats $(56,57)$. In the present study, $0.6 \mathrm{mg} / \mathrm{kg}$ Dex may be equivalent to a dose of $6 \mathrm{mg} /$ day in a $60-\mathrm{kg}$ individual, thus, comparable to the dose that is occasionally used in clinical treatment.

Rocuronium was used in the current study due to its chemical stability and common use in anesthesia (58). The concentration of rocuronium corresponding to $50 \%$ block $\left(\mathrm{EC}_{50}\right)$ under propofol anesthesia has been reported as $1.66 \mu \mathrm{M}$. The concentrations used in the present study were relevant to this effective dose $(59,60)$.

A limitation of the current study is that the persistent effect of Dex following discontinuation of GC was not examined. In a previous study, triamcinolone-induced weight loss and type II fiber atrophy recovered 3 weeks following cessation of the therapy (61). In patients with GC-induced myopathy, an increase in muscle strength may be observed within 3-4 weeks following discontinuation of the GC (16). In addition, it is unclear whether resistance to rocuronium changes over time. These areas require further investigation.

In conclusion, the results of the present study demonstrate that chronic Dex administration induces resistance to rocuronium in the rat diaphragm. A reduced distribution of type II fiber and associated changes in diaphragm function was noted. The observations indicate that resistance to rocuronium in a steroid-treated rat diaphragm is associated with Dex-induced fiber transformation.

\section{Acknowledgements}

This study was supported by the National Natural Science Foundation of China (no. 81171845). The authors would like to thank Liang Zhu (Department of Pharmacology, School of Medicine, Shanghai Jiaotong University) for technical assistance and support.

\section{References}

1. Azar I, Kumar D and Betcher AM: Resistance to pancuronium in an asthmatic patient treated with aminophylline and steroids. Can Anaesth Soc J 29: 280-282, 1982.

2. Laflin MJ: Interaction of pancuronium and corticosteroids. Anesthesiology 47: 471-472, 1977.

3. Meyers EF: Partial recovery from pancuronium neuromuscular blockade following hydrocortisone administration. Anesthesiology 46: 148-150, 1977.

4. Soltész S, Mencke T, Stunz M, Diefenbach C, Ziegeler S and Molter GP: Attenuation of a rocuronium-induced neuromuscular block in patients receiving prednisolone. Acta Anaesthesiol Scand 53: 443-448, 2009.

5. Soltész S, Mencke T, Mey C, Röhrig S, Diefenbach C and Molter GP: Influence of a continuous prednisolone medication on the time course of neuromuscular block of atracurium in patients with chronic inflammatory bowel disease. Br J Anaesth 100: 798-802, 2008.

6. Parr SM, Galletly DC and Robinson BJ: Betamethasone-induced resistance to vecuronium: a potential problem in neurosurgery? Anaesth Intensive Care 19: 103-105, 1991.

7. Arts WF and Oosterhuis HJ: Effect of prednisolone on neuromuscular blocking in mice in vivo. Neurology 25: 1088-1090, 1975.

8. Robinson BJ, Lee E, Rees D, Purdie GL and Galletly DC: Betamethasone-induced resistance to neuromuscular blockade: a comparison of atracurium and vecuronium in vitro. Anesth Analg 74: 762-765, 1992.

9. Parr SM, Robinson BJ, Rees D and Galletly DC: Interaction between betamethasone and vecuronium. Br J Anaesth 67: 447-451, 1991.

10. Dal Belo CA, Leite GB, Fontana MD, et al: New evidence for a presynaptic action of prednisolone at neuromuscular junctions. Muscle Nerve 26: 37-43, 2002.

11. Dalkara T and Onur R: Facilitatory effects of dexamethasone on neuromuscular transmission. Exp Neurol 95: 116-125, 1987.

12. Leeuwin RS, Njio KD, Belling GA and van den Hoven S: Glucocorticoid-induced changes in synaptic vesicles of rat phrenic nerve terminals. Arch Int Pharmacodyn Ther 266: 200-207, 1983.

13. Leeuwin RS, Veldsema-Currie RD, van Wilgenburg H and Ottenhof M: Effects of corticosteroids on neuromuscular blocking actions of d-tubocurarine. Eur J Pharmacol 69: 165-173, 1981.

14. Van Wilgenburg H, Njio KD, Belling GA and Van den Hoven S: Effects of corticosteroids on the myoneural junction. A morphometric and electrophysiological study. Eur J Pharmacol 84: 129-137, 1982.

15. Veldsema-Currie RD, Wolters E and Leeuwin RS: The effect of corticosteroids and hemicholinium-3 on choline uptake and incorporation into acetylcholine in rat diaphragm. Eur J Pharmacol 35: 399-402, 1976.

16. Pereira RM and Freire de Carvalho J: Glucocorticoid-induced myopathy. Joint Bone Spine 78: 41-44, 2011.

17. Yamamoto D, Maki T, Herningtyas EH, et al: Branched-chain amino acids protect against dexamethasone-induced soleus muscle atrophy in rats. Muscle Nerve 41: 819-827, 2010.

18. Inder WJ,Jang C, Obeyesekere VR and Alford FP: Dexamethasone administration inhibits skeletal muscle expression of the androgen receptor and IGF-1 - implications for steroid-induced myopathy. Clin Endocrinol (Oxf) 73: 126-132, 2010.

19. Schakman O, Gilson H, Kalista S and Thissen JP: Mechanisms of muscle atrophy induced by glucocorticoids. Horm Res 72 (Suppl 1): 36-41, 2009.

20. Schakman O, Gilson H and Thissen JP: Mechanisms of glucocorticoid-induced myopathy. J Endocrinol 197: 1-10, 2008.

21. Nava S, Gayan-Ramirez G, Rollier H, et al: Effects of acute steroid administration on ventilatory and peripheral muscles in rats. Am J Respir Crit Care Med 153: 1888-1896, 1996.

22. van Balkom RH, van der Heijden HF, van Herwaarden CL and Dekhuijzen PN: Corticosteroid-induced myopathy of the respiratory muscles. Neth J Med 45: 114-122, 1994.

23. Dekhuijzen PN, Gayan-Ramirez G, de Bock V, Dom R and Decramer M: Triamcinolone and prednisolone affect contractile properties and histopathology of rat diaphragm differently. J Clin Invest 92: 1534-1542, 1993.

24. Fletcher LK, Powers SK, Coombes JS, et al: Glucocorticoidinduced alterations in the rate of diaphragmatic fatigue. Pharmacol Res 42: 61-68, 2000. 
25. van Balkom RH, Dekhuijzen PN, Folgering HT, Veerkamp JH, Fransen JA and van Herwaarden CL: Effects of long-term low-dose methylprednisolone on rat diaphragm function and structure. Muscle Nerve 20: 983-990, 1997.

26. Van Balkom RH, Zhan WZ, Prakash YS, Dekhuijzen PN and Sieck GC: Corticosteroid effects on isotonic contractile properties of rat diaphragm muscle. J Appl Physiol 83: 1062-1067, 1997.

27. Dekhuijzen PN, Gayan-Ramirez G, Bisschop A, et al: Rat diaphragm contractility and histopathology are affected differently by low dose treatment with methylprednisolone and deflazacort. Eur Respir J 8: 824-830, 1995.

28. Sieck GC, van Balkom RH, Prakash YS, Zhan WZ and Dekhuijzen PN: Corticosteroid effects on diaphragm neuromuscular junctions. J Appl Physiol 86: 114-122, 1999.

29. Sieck GC and Prakash YS: Morphological adaptations of neuromuscular junctions depend on fiber type. Can J Appl Physiol 22: 197-230, 1997.

30. Prakash YS, Miller SM, Huang M and Sieck GC: Morphology of diaphragm neuromuscular junctions on different fibre types. J Neurocytol 25: 88-100, 1996.

31. Hemmerling TM and Donati F: Neuromuscular blockade at the larynx, the diaphragm and the corrugator supercilii muscle: a review. Can J Anaesth 50: 779-794, 2003.

32. Hemmerling TM, Schmidt J, Hanusa C, Wolf T and Schmitt $\mathrm{H}$ : Simultaneous determination of neuromuscular block at the larynx, diaphragm, adductor pollicis, orbicularis oculi and corrugator supercilii muscles. Br J Anaesth 85: 856-860, 2000.

33. Cantineau JP, Porte F, d'Honneur G and Duvaldestin P. Neuromuscular effects of rocuronium on the diaphragm and adductor pollicis muscles in anesthetized patients. Anesthesiology 81: 585-590, 1994.

34. Donati F, Meistelman C and Plaud B: Vecuronium neuromuscular blockade at the diaphragm, the orbicularis oculi, and adductor pollicis muscles. Anesthesiology 73: 870-875, 1990.

35. Pansard JL, Chauvin M,Lebrault C, Gauneau P and Duvaldestin P. Effect of an intubating dose of succinylcholine and atracurium on the diaphragm and the adductor pollicis muscle in humans Anesthesiology 67: 326-330, 1987

36. Donati F, Meistelman C and Plaud B: Vecuronium neuromuscular blockade at the adductor muscles of the larynx and adductor pollicis. Anesthesiology 74: 833-837, 1991.

37. Day NS, Blake GJ, Standaert FG and Dretchen KL: Characterization of the train-of-four response in fast and slow muscles: effect of d-tubocurarine, pancuronium, and vecuronium. Anesthesiology 58: 414-417, 1983.

38. Ma K, Mallidis C, Bhasin S, et al: Glucocorticoid-induced skeletal muscle atrophy is associated with upregulation of myostatin gene expression. Am J Physiol Endocrinol Metab 285: E363-E371, 2003

39. Burke RE, Levine DN, Tsairis P and Zajac FE III: Physiological types and histochemical profiles in motor units of the cat gastrocnemius. J Physiol 234: 723-748, 1973.

40. Brooke MH and Kaiser KK: Three 'myosin adenosine triphosphatase' systems: the nature of their $\mathrm{pH}$ lability and sulfhydry dependence. J Histochem Cytochem 18: 670-672, 1970.

41. Peter JB, Barnard RJ, Edgerton VR, Gillespie CA and Stempel KE: Metabolic profiles of three fiber types of skeletal muscle in guinea pigs and rabbits. Biochemistry 11: 2627-2633, 1972.

42. Sieck GC, Lewis MI and Blanco CE: Effects of undernutrition on diaphragm fiber size, SDH activity, and fatigue resistance. J Appl Physiol 66: 2196-2205, 1989.

43. Lewis MI, Sieck GC, Fournier M and Belman MJ: Effect of nutritional deprivation on diaphragm contractility and muscle fiber size. J Appl Physiol 60: 596-603, 1986.
44. Koerts-De Lang E, Schols AM, Wouters EF, Gayan-Ramirez G and Decramer M: Contractile properties and histochemical characteristics of the rat diaphragm after prolonged triamcinolone treatment and nutritional deprivation. J Muscle Res Cell Motil 19: 549-555, 1998.

45. Dekhuijzen PN, Gayan-Ramirez G, Bisschop A, De Bock V, Dom R and Decramer M: Corticosteroid treatment and nutritional deprivation cause a different pattern of atrophy in rat diaphragm. J Appl Physiol 78: 629-637, 1995.

46. Lewis MI and Sieck GC: Effect of acute nutritional deprivation on diaphragm structure and function in adolescent rats. J Appl Physiol 73: 974-978, 1992.

47. Van Wilgenburg H: The effect of prednisolone on neuromuscular transmission in the rat diaphragm. Eur J Pharmacol 55: 355-361, 1979.

48. Wilson RW, Ward MD and Johns TR: Corticosteroids: a direct effect at the neuromuscular junction. Neurology 24: 1091-1095, 1974.

49. Kotsarini C, Griffiths PD, Wilkinson ID and Hoggard N: A systematic review of the literature on the effects of dexamethasone on the brain from in vivo human-based studies: implications for physiological brain imaging of patients with intracranial tumors. Neurosurgery 67: 1799-1815, 2010.

50. Kularatne SA, Walathara C, Mahindawansa SI, et al: Efficacy of low dose dexamethasone in severe thrombocytopenia caused by dengue fever: a placebo controlled study. Postgrad Med J 85: 525-529, 2009.

51. Hardy JR, Rees E, Ling J, et al: A prospective survey of the use of dexamethasone on a palliative care unit. Palliat Med 15: 3-8, 2001.

52. Leeuwin RS and Wolters EC: Effect of corticosteroids on sciatic nerve-tibialis anterior muscle of rats treated with hemicholinium-3. An experimental approach to a possible mechanism of action of corticosteroids in myasthenia gravis. Neurology 27: 171-177, 1977.

53. Arts WF and Oosterhuis HJ: Long-term effect of glucocorticosteroids on neuromuscular blocking in mice. J Neurol Neurosurg Psychiatry 40: 675-677, 1977.

54. Wolters MJ and Leeuwin RS: Effect of corticosteroids on the phrenic nerve-diaphragm of preparation treated with hemicholinium. A possible model of myasthenia gravis. Neurology 26: 574-578, 1976.

55. Tomlinson ES, Maggs JL, Park BK and Back DJ: Dexamethasone metabolism in vitro: species differences. J Steroid Biochem Mol Biol 62: 345-352, 1997.

56. Crossland H, Constantin-Teodosiu D, Greenhaff PL and Gardiner SM: Low-dose dexamethasone prevents endotoxaemia-induced muscle protein loss and impairment of carbohydrate oxidation in rat skeletal muscle. J Physiol 588: 1333-1347, 2010

57. Kitano M, Ishinaga H, Shimizu T, Takeuchi K and Majima Y: Effects of clarithromycin and dexamethasone on mucus production in isografted rat trachea. Pharmacology 87: 56-62, 2011.

58. Proost JH, Eriksson LI, Mirakhur RK, Roest G and Wierda JM: Urinary, biliary and faecal excretion of rocuronium in humans. Br J Anaesth 85: 717-723, 2000.

59. Ito S, Nagata O and Ozaki M: Estimated blood concentration of rocuronium administrated by continuous infusion to maintain an appropriate neuromuscular blockade under propofol anesthesia. Masui 59: 82-86, 2010 (In Japanese)

60. Dragne A, Varin F, Plaud B and Donati F: Rocuronium pharmacokinetic-pharmacodynamic relationship under stable propofol or isoflurane anesthesia. Can J Anaesth 49: 353-360, 2002.

61. Braunstein PW Jr and DeGirolami U: Experimental corticosteroid myopathy. Acta Neuropathol 55: 167-172, 1981. 